\title{
COVID-19 Social Distancing and Emotional Health
}

\author{
K Jayanthi
}

\section{AbStract}

The outbreak of coronavirus disease 2019 (COVID-19) may be stressful for people and communities. Stress is an inevitable part of life. Coping with it has an effect on both physical and emotional states. Stress may be external and internal factors. Managing stress involves the tips to adapt to the external factors that confront and to the internal factors that strengthen the ability to manage. Stress management helps to cope with the stress and to lead a healthy life.

Keywords: Coping, COVID-19, Emotional health stress, Social distancing, Stress management.

Pondicherry Journal of Nursing (2020): 10.5005/jp-journals-10084-12141

\section{INTRODUCTION}

The coronavirus disease 2019 (COVID-19) outbreak is stressful for the people and communities.

It is to realize that social distancing does not have to mean social isolation with ease of modern technologies available for many. ${ }^{1}$

\section{Stress And Coping}

Stress is an inevitable part of life. Coping with it affects both physical and emotional states. Stress may be related to external and internal factors. ${ }^{2}$

\section{External Factors}

- Physical environment

- Relationships with others in job

- Relationships with others in home

- Situations that challenges, involves difficulties, and makes expectations that confronted daily

\section{Internal Factors}

- The ability of body that responds to and deals to the external factors that induces stress.

\section{Internal Factors that Influence Stress Handling}

- Health and fitness level

- Level of nutritional status

- Emotional well-being status

- Relaxation techniques and other stress-reducing strategies

- The amount of rest and sleep

The learning tips help to manage stress and involve changing the factors that confront which is external and the factors that help to strengthen the ability to deal which is internal. ${ }^{3}$

\section{Stress And COVID-19}

- Disbelief

- Anxiety

- Fear

- Feeling of numbness
Department of Mental Health Nursing, Kasturba Gandhi Nursing College, Sri Balaji Vidyapeeth, Puducherry, India

Corresponding Author: K Jayanthi, Department of Mental Health Nursing, Kasturba Gandhi Nursing College, Sri Balaji Vidyapeeth, Puducherry, India, Phone: +919629684131, e-mail: sanjayanthi1328@ gmail.com

How to cite this article: Jayanthi K. COVID-19 Social Distancing and Emotional Health. Pon J Nurs 2020;13(3):66-67.

Source of support: Nil

Conflict of interest: None

- Changes in appetite

- Changes in energy

- Changes in level of activity

- Difficulty to concentrate

- Difficulty to sleep

- Getting nightmares

- Thoughts and images that makes to upset

- Physical reactions like headache, body pain, skin rashes, and stomach problem

- Worsening of chronic health problems

- Showing anger and short temper

- The tobacco, alcohol, and drugs use are increased. ${ }^{4}$

\section{Coping AND COVID-19}

\section{Stay Informed}

When thinking of some information is missing, that leads to more stressful, nervousness. Read, listen, or watch official newspapers or news sites for the updates about the outbreak. There may be various rumors especially during the time of a crisis COVID-19, on the social media. Have a check with the reliable source of information like local government authorities always.

\section{Take Breaks}

Take a break from social media about COVID-19 false stories by listening to, watching, and reading. Hearing and seeing the images about the pandemic repeatedly seems to be upsetting. Plan to do the enjoyable activities as much as possible and return to normal life and check for updates between the breaks.

\footnotetext{
(c) The Author(s). 2020 Open Access This article is distributed under the terms of the Creative Commons Attribution 4.0 International License (https://creativecommons. org/licenses/by-nc/4.0/), which permits unrestricted use, distribution, and non-commercial reproduction in any medium, provided you give appropriate credit to the original author(s) and the source, provide a link to the Creative Commons license, and indicate if changes were made. The Creative Commons Public Domain Dedication waiver (http://creativecommons.org/publicdomain/zero/1.0/) applies to the data made available in this article, unless otherwise stated.
} 


\section{Taking Care of Body}

Meditate, do stretching exercises, and also do deep breathing exercises. Always eat a well-balanced and healthy diet as meals daily, have good sleep, and should avoid tobacco, alcohol, and other types of drugs.

\section{Make Time to Enjoy}

Try to do some pleasurable activities that make you enjoy and it will remind that strong feelings will fade.

\section{Connect with Others}

Having good connectivity with friends and loved ones is possible utilizing phones and it helps us to maintain the connection during the stressful days ahead and it also gives us the strength to weather the difficult passage. Always maintain a healthy relationship to build a strong support system.

Talk with people you trust, may be friend or family member, about your concerns and how you are feeling.

\section{Seek Help if Needed}

If activities of daily living are affected due to distress for several days to weeks, contact through helpline, talk with a counselor, or doctor. ${ }^{5,6}$

\section{Stress Management and Emotional HeALTH}

If feeling that facing an unbearable stress and unable to cope with that stress or manage on their own, there are some resources that help to overcome stress.

\section{Consult with Doctor}

Stress takes its toll by bringing changes in the body; it may lead to increasing susceptibility of the infections, which makes the symptoms to get worsening of any type of chronic condition. And stress is considered to be a cause of numerous types of physical symptoms.

The effect of the stress on the physical functioning is assessed by the physician. The extent of the stress experience must be ventilated honestly to the physician. The physician recommends the ways to overcome these types of negative influences due to stress.

The physician suggests the possibility of usage of medications that helps in the severe cases of the short-term life stress to alleviate the short-term symptoms.

Relaxation techniques and tips on the stress-reduction strategies are suggested which is most appropriate in reduction of stress. The doctor acts as a good referral source who guides to seek guidance from a counselor or from the psychotherapist.

\section{Consider Counseling}

The mentalhealth professional offers various types of stressmanagement techniques and counseling. The therapy has a proven benefit in the reduction of symptoms due to stress and helps to improve the level of overall attitude and health status through the group discussion therapy and the stress counseling.
Counseling from a qualified therapist for some people is beneficial with a series of planned stress-counseling sessions and is not considered as a long-term commitment.

$\mathrm{He} /$ she can help you identify the problem areas in your life and work on strategies to control your most stressful moments or situations.

The act of ventilating through talking with a supportive person who acts as an observer helps to identify the problem areas in life, suggests strategies to control the stressful moments, and will help to unleash the tension and worry in a great way.

\section{Spending Time}

Always have a balanced way in spending the time. Spend time with the people those who you love, have a good social support system with friends, happy family, and liked pets. This will help to experience a less in the stress-related symptoms.

\section{Engage in a Course}

The methods for emotional and physical relaxation, many relaxation programs, and meditation techniques are learned processes that can be learnt quickly from a competent instructor/trainer. ${ }^{7}$

\section{Conclusion}

Stress management involves learning to change external factors that will confront and the internal factors, which help to strengthen the ability to deal the emotional health. ${ }^{3}$ Stress management helps to cope with the stress in social distancing and balances emotional health, which helps to lead a healthy life in this COVID-19 outbreak. ${ }^{4,6}$

\section{References}

1. University of Maryland School of Medicine. "Anxious about COVID19 ? Stress can have lasting impacts on sperm and future offspring: Study identifies biological mechanism by which stress alters sperm and impacts brain development in next generation." ScienceDaily. ScienceDaily, 2020. Retrieved from www.sciencedaily.com/ releases/2020/03/200323132410.htm.

2. Centers for Disease Control and Prevention. 2019 Retrieved from https://emergency.cdc.gov/coping/selfcare.asp.

3. Centers for Disease Control and Prevention. (2012). Lesson One: Epidemiology. Retrieved from https://www.cdc.gov/csels/dsepd/ ss1978/lesson1/section11.html.

4. Stress Management. Retrieved from https://www.medicinenet.com/ stress_management_techniques/article.htm.

5. The Anxiety and Depression Association of America (2020). Stress. Retrieved from World Health Organization. (2020). Coronavirus Mental Health Considerations. Retrieved from https://www.who.int/ docs/default-source/coronaviruse/mental-health-considerations. pdf?sfvrsn=6d3578af_10.

6. Centers for Disease Control and Prevention. (2019). Coping with Stress. Retrieved from https://www.cdc.gov/violenceprevention/suicide/ copingwith-stresstips.html.

7. Melissa Cornad Stoppler. Stress Relief. 10 Ways to Stop Stress. Coronavirus. COVID-19. Latest News and Information. 2020. 